\title{
Musik Garap Emotion of Sikatuntuang Sebagai Media Kreatif Musikal Siswa Sekolah Dasar
}

\section{Wimbrayardi}

Sendratasik Fakultas Bahasa dan Seni

Universitas Negeri Padang

wimbrayardi@gmail.com

\section{Irdhan Epria Darma Putra}

Sendratasik Fakultas Bahasa dan Seni

Universitas Negeri Padang

irdhan@fbs.unp.ac.id

\section{Bambang Parmadi}

PGSD FKIP Universitas Bengkulu

bparmadie@unib.ac.id

\begin{abstract}
Music is a sound that is gotten by people and fluctuates dependent on history, area, culture and individual preferences. The genuine meaning of music additionally shifts, including that (1) music is a sound/impression of something that is caught by the audience's detects, (2) music is a showstopper with all its primary and supporting components, and (3) music is all sounds. delivered deliberately by an individual or by a gathering of people introduced as music. From a portion of these definitions, music is all sounds created by people purposefully which are introduced as music. Different examinations have shown that improving music knowledge in grade school understudies should be possible differently, including (1) presenting music in the homeroom, (2) tuning in to music, (3) playing instruments in class. For each reason, the class is improved with music utilizing a wide range of methods. The utilization of music in the homeroom will help increment the fervor of elementary school understudies in learning and simultaneously can expand the adequacy of accomplishing objectives. No less significant is learning through music and additionally learning with music, and finding out about music can give numerous advantages to the physical and mental improvement of elementary school understudies.
\end{abstract}

Keyword: Learning, Traditional, Musical

\section{Pendahuluan}

Kesenian adalah salah satu unsur dari kebudayaan yang berpotensial bagi pembangunan nasional. Berkesenian mencerminkan ke-Bhineka Tunggal lka-an dan sebagai penunjang pembangunan nasional. Pembinaan dan pengembangan kesenian adalah salah satu upaya untuk memelihara dan melestarikan serta meningkatkan mutu kebudayaan. Dalam mewujudkan terbinanya pembangunan seni (kesenian) perlu dilakukan kesinambungan yang terus menerus, maka peranan pemerintah dan masyarakat sangat menentukan.

Pelajaran seni musik dimaksudkan untuk menumbuhkan rasa kasih sayang, cinta, dan kebanggaan dalam ekspresi manusia terhadap budaya negaraa sendiri. Demikian pula, pengajaran kesenian bertujuan untuk menumbuhkan kapasitas emosional dan antusias siswa sekolah dasar dalam memahami pelajaran kesenian. Bersama-sama 
agar latihan pembelajaran dapat berjalan dengan baik, para pendidik juga dituntut dan diharapkan untuk berusaha sekuat tenaga untuk menumbuhkan kapasitas dan inspirasi serta pengendalian sehingga kebermanfaatan instruktur benar-benar diwujudkan oleh alam semesta pelatihan. Berawal dari itu, dibutuhkan inspirasi dan fokus dari siswa untuk memahami semua topik yang diajarkan oleh guru. Setelah mengalami kesempatan belajar, siswa merespon dalam diri mereka. Siswa dapat mengoordinasikan informasi yang mereka peroleh, dan itu harus dipahami dan harus diulang sampai menjadi milik mereka untuk mengubah mentalitas dan perilaku mereka.

Dengan demikian pendidikan di Sekolah Dasar yang merupakan pondasi bagi peserta didik dalam mengikuti pendidikan formal, wajib mengajarkan seluruh mata pelajaran yang ada dalam kurikulum.Termasuk mata pelajaran kesenian (Musik). Musik adalah bagian penting dari kehidupan, oleh karena itu, musik harus menjadi bagian penting dari wawasan sekolah. Banyak hasil eksplorasi yang mengungkap bahwa musik telah dimanfaatkan untuk memberikan inspirasi dalam bidang matematika, sosiologi, ekspresi bahasa, sains, sejarah, dll. Musik adalah bahasa yang tersebar luas, sehingga cenderung menyatu dalam semua bidang studi. untuk memberikan pembelajaran. Karena musik dapat membantu sekolah menjadi tempat yang menyenangkan, dan musik memiliki tempat bersama anak-anak. Sejalan dengan itu, pendidik harus memanfaatkan inspirasi belajar yang dijiwai oleh musik ini. Untuk mengkoordinasikan musik dalam pembelajaran, sangat baik dapat dilakukan melalui prosedur yang berbeda. Seperti pada jam belajar, instruktur dapat memainkan musik untuk membuat rileks dan semangat bagi siswa. Musik adalah bantuan untuk siswa. Mereka energik untuk mengikuti latihan belajar dan memberikan tekanan dalam menyelesaikan latihan. Penelitian menunjukkan bahwa musik memberikan banyak manfaat bagi orang atau siswa seperti menghidupkan otak, meningkatkan daya ingat dan daya ingat, dan memiliki kemampuan untuk menciptakan pengetahuan yang menarik. Musik juga dapat menyesuaikan kemampuan otak kiri dan otak kiri, yang berarti menyesuaikan perkembangan pandangan ilmiah dan semangat. Sampai saat ini ada dugaan bahwa musik yang dapat berdampak positif dan mendidik otak adalah musik. "Musikalitas, lagu, dan konkordansi musik dapat menjadi pendorong untuk meningkatkan kapasitas belajar siswa sekolah dasar. Melalui siswa musik secara efektif menangani hubungan antara waktu, jarak dan aransemen (suksesi) yang merupakan kemampuan yang diperlukan untuk kemampuan dalam penalaran yang konsisten. Musik diterima secara luas untuk memiliki pilihan untuk memulai pikiran kreatif dan mengeluarkan hal-hal rahasia yang disimpan oleh seseorang. Musik juga dapat menghidupkan hubungan antara neuron. Jadi, ketika seseorang mendengarkan musik, itu berarti bahwa bagian-bagian tertentu dari saraf dianimasikan untuk selalu bergaul Ketika seseorang mendengarkan musik, terutama musik yang lembut, itu dapat membuat suasana menjadi nyaman dan ketika pikiran terasa baik, biasanya otak akan bekerja dengan baik.

\section{Metode}

Penelitian pengembangan model ini dilakukan dengan menggunakan desain reaearch kualitatif dengan pendekatan analisis taksonomi (Saldana dalam Milles, 2009:78). Penelitian ini diarahkan ke Sekolah Dasar, sedangkan sekolah dasar dalam ruang dipilih dan diputuskan secara purposive. Subyek penelitiannya adalah para pendidik, pengelola sekolah, dan murid-murid serta ahli dalam Pendidikan dan pembelajaran seni musik. Teknik pengumpulan data dilakukan dengan memanfaatkan persepsi atau amatan, latihan musik dan wawancara. Partisipan yang terlibat dalam penelitian ini adalah guru dan siswa sekolah dasar di Kota Padang, yang menjadi sumber data utama adalah siswa atau data guru dan seniman pelaku serta dokumetasi. 
Instrumen adalah alat yang digunakan untuk mengumpulkan data. Instrumen utama pada penelitian adalah peneliti sendiri, yang didukung oleh instrument pendukung dengan praktik langsung. Disamping itu, wawancara dan focus group discussion (FGD) dilakukan terhadap sejumlah informan dan pelaku untuk mendapatkan gambaran secara komprehensif tentang persepsi dan respons, padangan, sikap, serta ditambah dengan studi dokumentasi pada detail karya. Sedangkan observasi dilakukan untuk mendeskripsikan gambaran riil di lapangan tentang kondisi pengembangan pada karya Emotion of Sikatuntuang. Sedangkan kegiatan

Untuk dapat mengatasi masalah tersebut, teknik snowball sebagai salah satu teknik nonprobabilitas dapat digunakan untuk pengumpulan data guna menjawab permasalahan penelitian. Snowball merupakan salah satu bentuk judgment research. Teknik penentuan informan yang mula-mula berjumlah kecil, kemudian membesar.

Pada tingkat operasionalnya teknik snowball, yaitu informan yang relevan diwawancara dan diminta untuk menyebutkan atau menunjukkan informan dan pelaku lainnya.

Sedangkan Teknik analisis data dalam penelitian ini dilakukan dengan menggunakan metode analisis deskripsif yang jelas. Pada konteks pengembangan, teknik analisis data menggunakan model analisis interaktif dan menkondensasi data. Pada penelitian ini, verifikasi data dilakukan secara terus menerus sepanjang proses penelitian dilakukan, Milles, dkk (2014:223).

\section{Hasil}

Musik mempengaruhi fisik dan mental orang serta kepribadian masyarakat. Secara luas, bagian musik dalam pengembangan perilaku adalah sebagai pembangunan karakter yang mendasar atau musik mempunyai andil sebagai "root" dalam ahklak dan tata krama, membentuk moral yang baik dan menuntun perilaku keadilan, cinta dan kelembutan. Musik dan karakter budi pekerti memiliki hubungan yang kuat dalam aturan keindahan, pedoman kesesuaian, dan aturan ukuran dan kapasitas. Seperti pada Bulletin of the Council for Research in Music Education, beberapa diantaranya adalah sebagai berikut. 1) Pendidikan seni/musik, bekerja untuk peningkatan anak-anak dalam bahasa dan kecepatan membaca. 2) Aktivitas musik atau berkesenian sangat penting bagi perkembangan anak-anak dalam kreatifitas dan lain-lain. 3) Aktivitas musik atau berkesenian mendorong perkembangan sikap baik terhadap sekolah dan mengurangi pembolosan siswa dari sekolah. 4) Kontribusi dalam kegiatan musik/berkesenian secara lugas meningkatkan ekspresi. 5) Pensisikan seni/musik bekerja memudahkan perkembangan sosial, perubahan, dan perkembangan intelektual.

Pembelajaran seni musik merupakan materi yang berperan penting dalam membantu kemajuan individu siswa yang akan mempengaruhi pada perkembangan akal, otak, sosialisasi, dan perasaan. Ada komponen melodi yang harus digarisbawahi dalam musik yang dikuasai, antara lain: 1. Suara, merupakan komponen melodi dalam membuat karya melodi, dalam kuatnya kita menemukan nada (padat tinggi dan rendah), nada (susunan nada). 2. Mood, perkembangan musik yang berjalan secara konsisten yang tidak terlihat dalam nada namun dapat dirasakan setelah melodi dimainkan. Irama juga memiliki istilah lain, yaitu musikalitas. Mood atau beat adalah rencana suara sesuai jadwal. Irama itu sendiri adalah sepotong nada atau nada. Dalam sebuah musikalitas terdapat dokumentasi cadence sebagai not dan tanda hening, ritme yang merupakan penegasan cepat dan sedang dalam melodi. 3. Irama dapat diuraikan sebagai ketukan mantap yang menarik kuat ke dalam ketukan tunggal. Untuk situasi ini ritme dapat diartikan sebagai satuan waktu normal ketika 
sebuah musik dimainkan yang menggambarkan kecepatan musik. Dalam bermain musik kita tidak boleh mendahului atau melampaui lebih lambat dari ritme. 4. Nada dikenal sebagai bayangan suara. Untuk situasi ini, nada sangat dipengaruhi oleh sumber suara dan cara getaran atau bunyinya. 5. Unsur adalah bagian musik yang diidentikkan dengan tingkat kegaduhan bunyi. Gambar-gambar melodi yang memperjelas unsur-unsur musik seperti piano (halus) dan titik kuat (riuh). 6. Menjelang level awal, perangkat yang mudah dimainkan harus digunakan. Biasanya alat musik irama menaungi alat musik melodis, jadi permainannya adalah permainan ketukan, maka permainan musik itu terus menerus dan dapat diberikan permainan melodi.

Kreatifitas adalah kemampuan individu untuk menciptakan hal baru dan inovatif. Demikian pula, imajinasi adalah sesuatu yang esensial baik dari segi individu maupun sosial, dan dapat dimunculkan dengan merenungkan karya-karya yang dilindungi yang ada. Proses pembelajaran kreatifitas pada dasarnya adalah untuk mendorong berbagai pilihan pemikiran yang berbeda untuk mengatasi sesuai dengan apa yang ada pada mereka. Menurut Munandar (1999: 21), bahwa siklus imajinatif mencakup empat fase, yaitu (1) persiapan; (2) inkubasi; (3) iluminasi; (4) verifikasi. Motivasi lain mengapa kreativitas diperlukan dalam pembelajaran musik adalah aktivitas musik itu sendiri benar-benar mendukung penciptaan yang membutuhkan kreativitas. Oleh karena itu, setiap siswa harus diberi kesempatan yang luas untuk mencari pengalaman bermusik. Melalui musik seorang siswa dapat menumbuhkan ruang imajinasi dan kreasi, ekspresi diri, dan kreativitas.

Untuk situasi ini, guru harus kreatif, profesional, dan menyenangkan. Hal ini, dapat dilakukan dengan: (1) orang tua sebagai patner, (2) pendamping dan mengkomunikasikan perhatian untuk siswa, (3) fasilitator yang selalu siap memberikan kenyamanan, melayani siswa sesuai dengan minat, kemampuan, dan bakat mereka, (4) memberikan masukan kepada orang tua untuk menemukan masalah yang dihadapi anak dan membantu mengatasinya, (5) mendorong rasa percaya diri, berani bertanggung jawab, (6) memperkenalkan anak-anak satu sama lain (dalam kelompok) dengan orang lain dengan cara yang masuk akal, (7) menumbuhkan proses sosialisasi yang tepat antara anak-anak, orang lain, dan iklim, (8) menumbuhkan inovasi/kreativitas, (9) menjadi mitra bila diperlukan. Untuk memenuhi kebutuhan di atas, pendidik harus memiliki pilihan untuk menguraikan pembelajaran sebagai metode untuk membangun kemampuan dan meningkatkan sifat individu anak-anak. Ada banyak hal yang harus dilakukan instruktur dalam menguraikan pembelajaran dan secara tidak langsung akan meningkatkan metodologi dan kemampuan yang dipoles dari pendidik. Memuaskan setiap pekerjaan yang harus dimiliki seorang pendidik bukanlah pekerjaan yang mudah. Seorang pendidik perlu melakukan upaya yang solid untuk mengakui atau memenuhi permintaan untuk meningkatkan keterampilan yang dipoles. Guru harus kreatif dalam memanfaatkan metode dan media yang inovatif, memodifikasi materi pembelajaran, mengembangkan pembelajaran yang memungkinkan setiap anak untuk bekerja dengan kapasitasnya masing-masing pada setiap materi dan mendorong keterlibatan anak disetiap kegiatan pembelajaran.

Dengan berfokus pada karakter guru, pendidik harus merencanakan secara tepat dan efektif segenap kemampuan pribadi dan kemampuan akademis. Seorang guru yang akan memberikan pembelajaran pendidikan musik, tentunya harus memahami dasardasar teori musik, baik itu tentang ritem atau pola irama, nada/melodi, dan vokal mengenai praktik musik itu sendiri. 


\section{Pembahasan}

Parmadie (2017:161), dalam artikelnya, tentang "Dinamika Musik Dol Sebagai Media Pendidikan Seni Di Kota Bengkulu" mengemukakan "semua fenomena-fenomena yang terjadi dari dinamika media pembelajaran musik baik secara sarana inovasi pendidikan maupun secara musikal itu sendiri sangat jelas berpengaruh terhadap perkembangan musik tradisi secara sosiokultural, secara kompetensi guru, dan perkembangan kognitif dan motorik siswa". Berdasarkan pada pendapat di atas ada beberapa pola inovasi pembelajaran seni musik sebagai media kreatif musical untuk siswa sekolah. khususnya pada Sekolah Dasar.

Selanjutnya pada proses penciptaan karya, menurut Tolah (2014:44) mengatakan bahwa "mencipta karya tahap "persiapan" dan melalui sebuah "tempat". Kenyataan ini dapat dilihat dari proses bagaimana karya-karya musik distorsi akustik diciptakan". Tahapan untuk menghasilkan karya musik pada konteks proses kreatif adalah prepasi, inkubasi, iluminasi, dan verifikasi. Karsono, (2011:41) mengatakan bahwa "kenyataan-kenyataan yan terjadi dalam proses penciptaan merupakan elemen penting dalam sebuah proses maupun dalam produk karyanya".

Tahapan dan penerapan karya musik Emotion Of Sikatuntuang sebagai media kreatif musical di sekolah adalah adalah, sebagai berikut.

\section{Implementasi Emotion Of Sikatuuntuang di Sekolah Dasar}

Tujuan pengajaran music Emotion of Sikatuntuang di Sekolah Dasar harus diubah menjadi beberapa tujuan informatif umum (TIU) sesuai dengan kumpulan komponen melodi dasar, khususnya irama, lagu, harmoni, struktur/konstruksi, dan artikulasi. Tujuan informatif keseluruhan untuk mengajar musik di sekolah dasar dapat dibentuk sebagai berikut.

a. Siswa dapat memiankan alat musik sikatuntuang (berupa balok kayu) yang berkaitan dengan irama, dan siswa bisa merasakan irama melalui pengalaman dan penghayatan musik, mempunyai bayangan penginderaan pola irama, membuat pola-pola irama sederhana, dan membaca notasi pola irama dengan benar. Bentuk karya seni Emotion of Sikatuntuang, tentu harus disesuaikan dengan tingkat kemampuan siswa Sekolah Dasar. Dalam praktek secara gagasan musikal, mengambil dasar dari bermacam pengembangan motif-motif ritem yang menjadi landasan pola ritem dari kesenian Sikatuntuang (balok kayu).

b. Siswa dapat memiliki pengetahuan tentang melodi dari permainan Emotion of Sikatuntuang, merasakan melodi melalui pengalaman dan penghayatan musik.

c. Siswa dapat memiliki pengetahuan tentang harmoni dalam permainan Emotion of Sikatuntuang, dan siswa merasakan melalui pengetahuan dan penghayatan musik, mempunyai bayangan penginderaan gerak harmoni.

d. Siswa dapat memiliki pengetahuan tentang struktur dari permainan pola irama melalui pengalaman Emotion of Sikatuntuang.

e. Siswa dapat pengetahuan tentang ekspresi, merasakan ekspresi melalui pengalaman dan penghayatan musik Emotion of Sikatuntuang, mempunyai penginderaan bermacam tingkat ekspresi.

Kreativitas dalam pembelajaran musik diharapkan dapat memperoleh informasi, pengetahuan, pemahaman, dan penguasaan musik yang ideal karena musik itu sendiri memiliki banyak ukuran kreatif. Misalnya, dalam musik ada analogi melalui 
anggapan, visual, pendengaran, antisipasi, penalaran induktif-deduktif, memori, fokus, dan masuk akal. Pola musikal berpusat pada isu-isu penting seperti perspektif atau "musik baru" yang memberikan kesempatan untuk mencapai tujuan metodologis dan komposisi tertentu. Tujuan ini akan dicapai melalui peningkatan memori, improvisasi dan fokus yang akan diberikan pada siswa. Musik kreatif ini harus dimungkinkan dengan mengajak anak-anak menemukan materi atau media baru untuk dimanfaatkan sebagai instrument musik (baik tradisi maupun ekasperimen), sehingga dapat mengeluarkan imajinasi mereka dalam bermusik. Misalnya, dengan memanfaatkan instrumen atau perangkat konvensional di sekitar mereka seperti kendi, tong, wadah, bambu, batu, mereka membuat instrumen inovatif dan memainkannya dengan kreativitas mereka.

Secara keseluruhan pembelajaran musik konvensional, sekadar mengetahui cara memainkan atau mempraktikkan alat musik tradisional Sikatuntuang (kotak kayu) dari awal hingga akhir. Sehingga memungkinkan anak-anak untuk memahami musik secara keseluruhan, dan dapat menerapkannya secara nyata sesuai dengan bakat/kemampuan siswa. Hal ini juga membuat perbedaan antara siswa yang menggunakan kreativitas dalam mengikuti pembelajaran musik dan siswa yang ditunjukkan menggunakan teknik reguler dalam pembelajaran. Siswa yang mengikuti latihan musik dengan menerapkan komponen daya cipta dapat melihat atau mempertimbangkan hal-hal yang fenomenal, aneh, menggabungkan data yang tampaknya terputus dan memancarkan aransemen baru atau pemikiran inovatif, yang menunjukkan keakraban, kemampuan beradaptasi, dan kreativitas dalam bernalar. Selain itu, siswa merasa senang dan bersemangat karena mereka diberi kesempatan untuk berkreasi dan berinovasi melalui musik. Contoh yang dimainkan oleh siswa sekolah dasar adalah sebagai berikut

\section{a. Permainan Praktek I Pola dari Emotion Of Sikatuntuang}

Permainan pada praktek bagian I Bagian ini merupakan ungkapan tentang pemahaman terhadap pola irama dari Sikatuntuang.Bentuk ini didekatkan kepada emosional, akan timbul rasa kebersamaan dalam keakraban siswa Sekolah Dasar. Pada bagia praktek I ini menggunakan alat kesenian tradisi Sikatuntuang dari permainan pola-pola ritem dan melodi Kesenian Sikatuntuang.

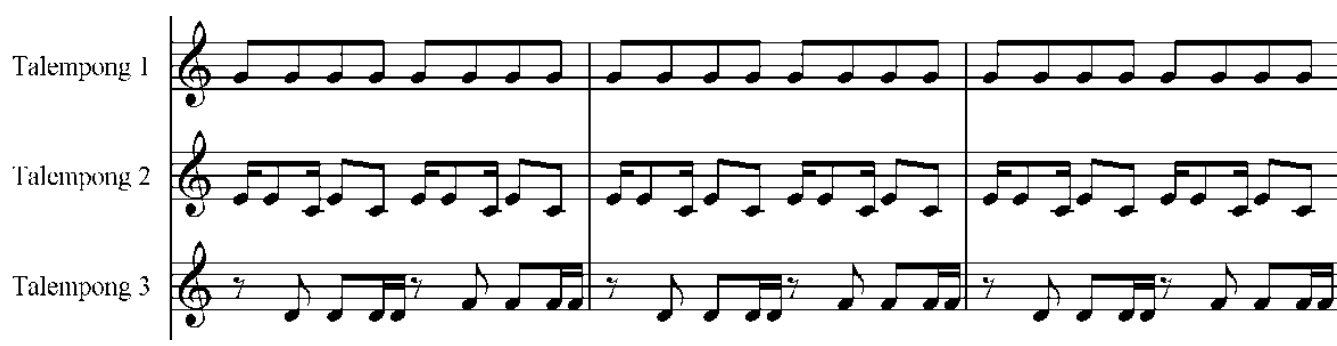




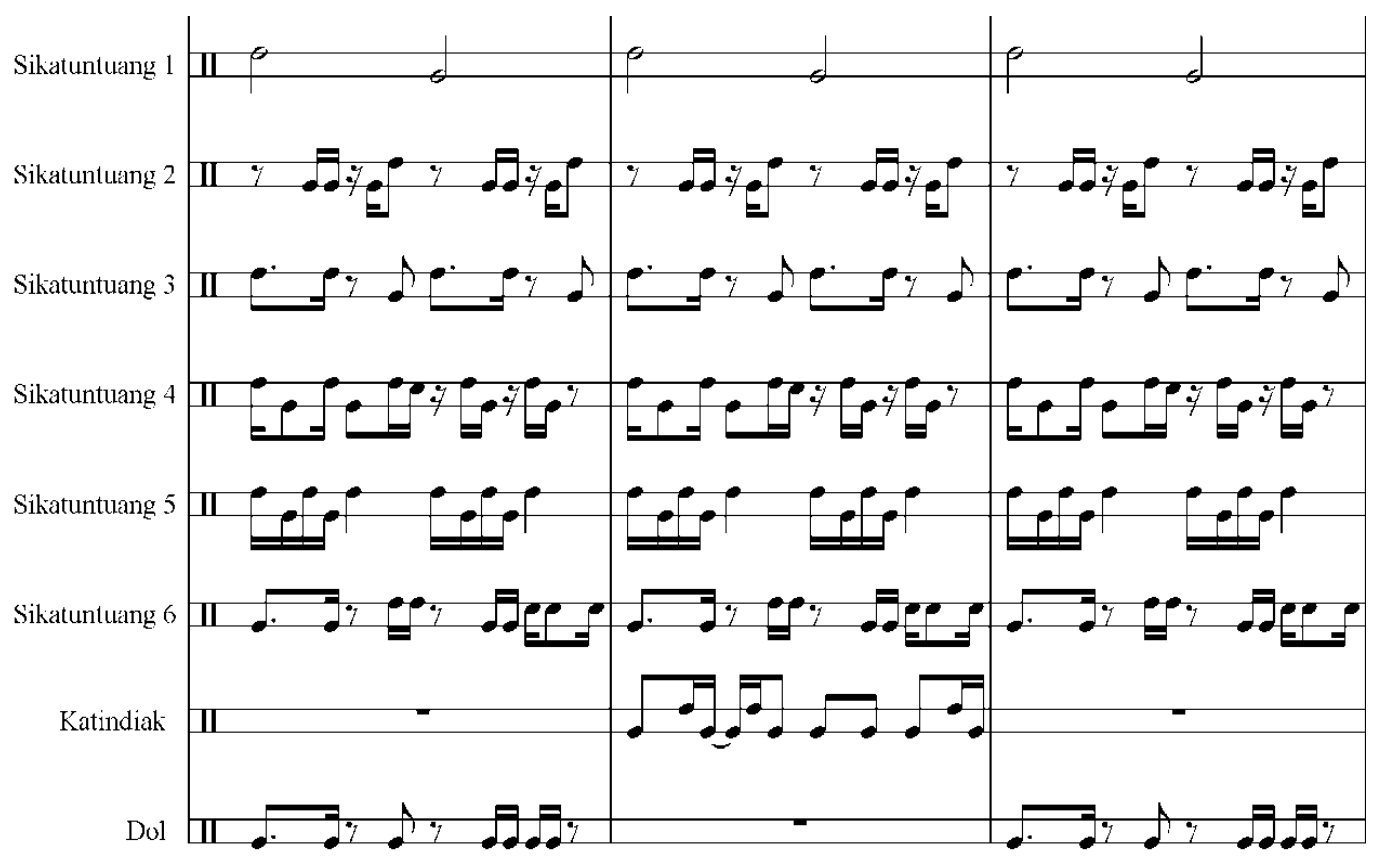

b. Permainan Praktek II Pola dari Emotion Of Sikatuntuang

Pada permainan praktek II ini, lebih menekankan kepada permainan polar item dan tempo agar terbangun rasa kegembiraan sebagai suatu emosional dari kesenian Sikatuntuang.

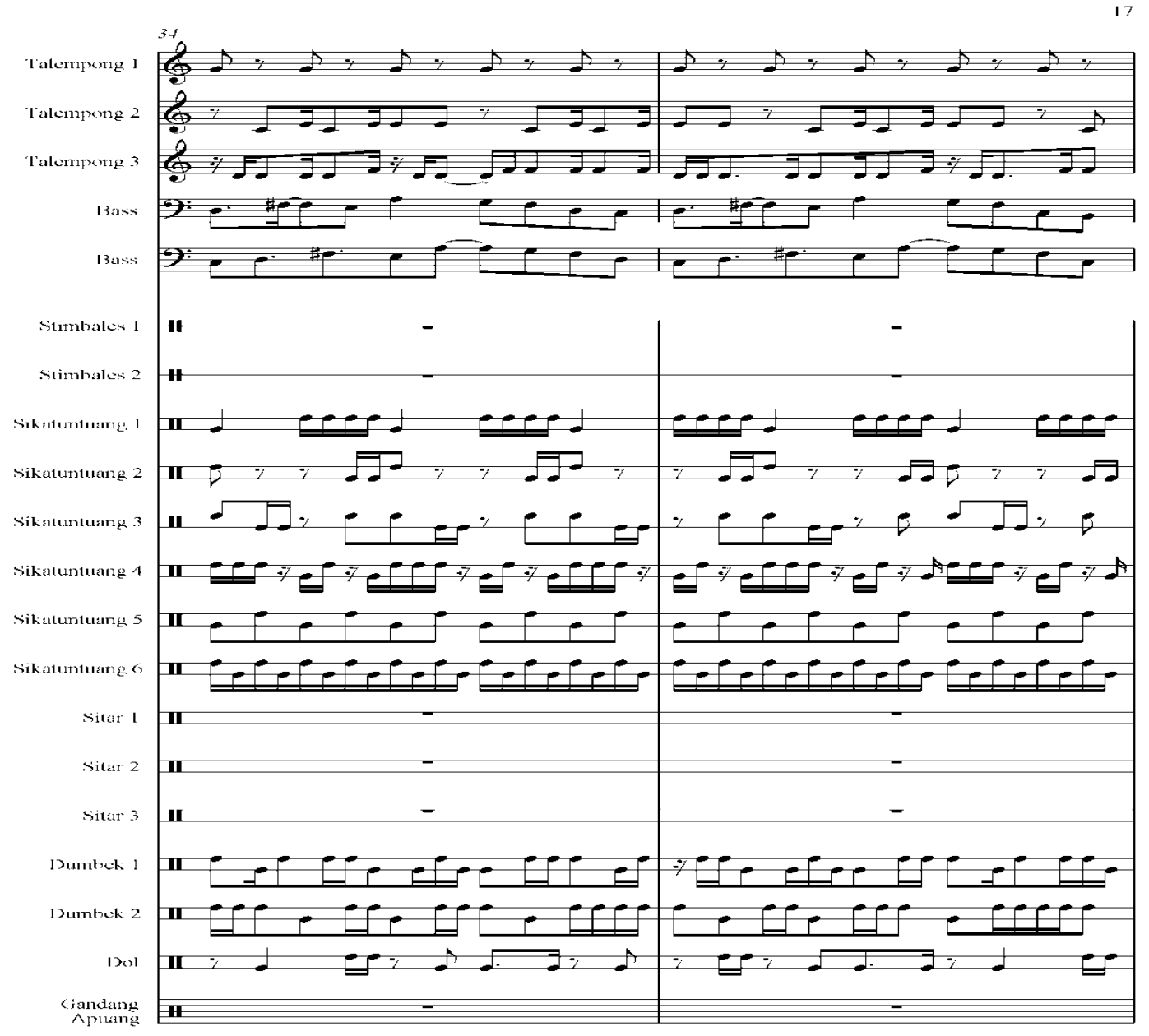


c. Permainan Praktek III Pola dari Emotion Of Sikatuntuang

Bagian permainan praktek III ini lebih mengutamakan bentuk "Emosional", yang mana bentuk akan memungkin muncul rasa bagi siswa-siswa yang memainkannya dan siswa juga merasakan kesenian tradisi sebagai produk bentuk "baru". Dalam praktek permainan Emotion Of Sikatuntuang, mencoba memaksimalkan penggunaan peralatan agar siswa betul memunculkan rasa emosi dan motivasi dalam diri siswa tersebut, dan siswa juga merasakan menyangkut warna bunyi dan karakter alat-alat yang dimainkan oleh siswa.

I

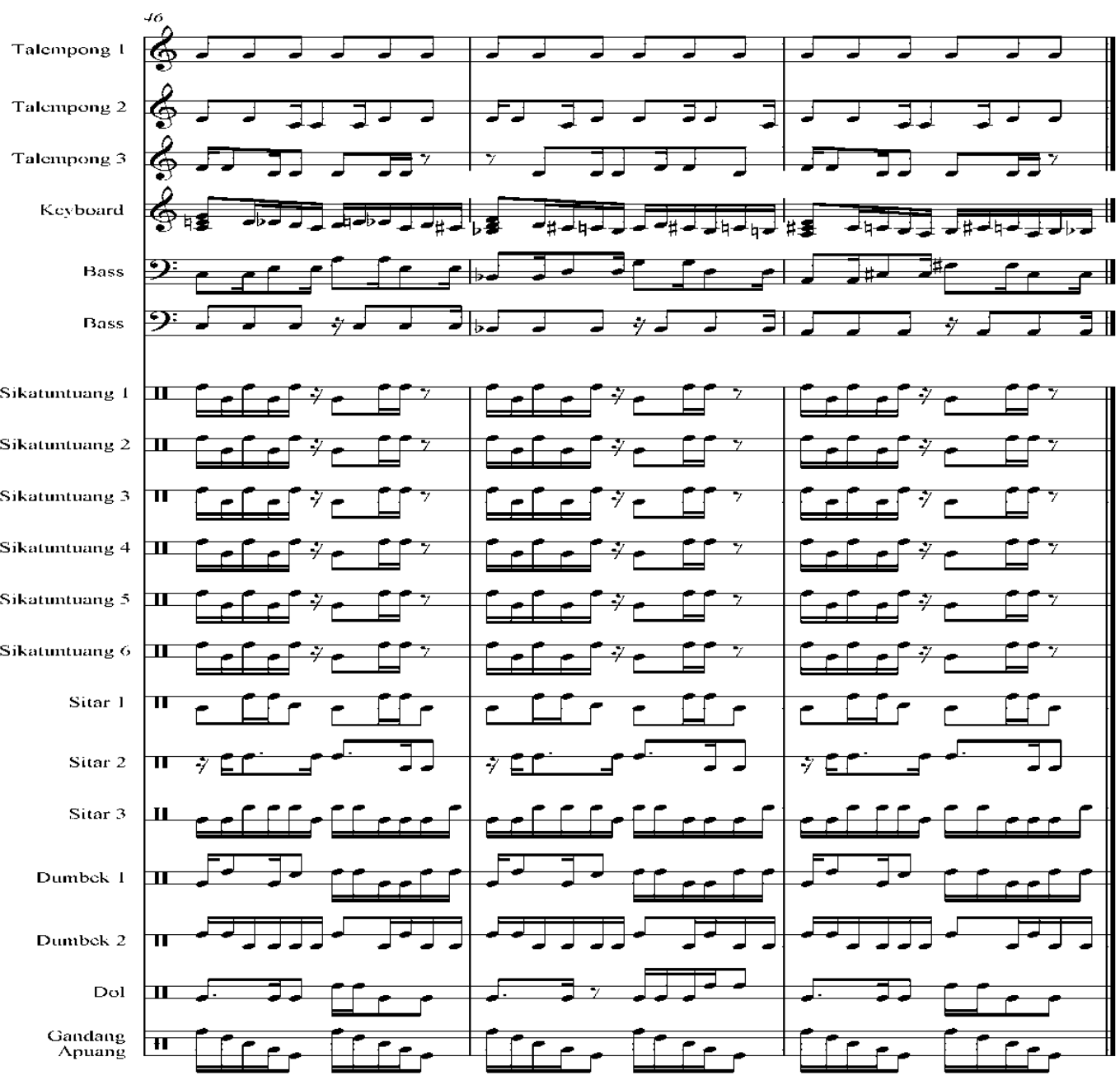

\section{Simpulan}

Guru pada umumnya akan mengkaji materi pembelajaran dengan memanfaatkan strategi bicara, dan praktik, seperti halnya bermain atau berlatih musik Sensasi Sikatuntuang dari awal hingga batas terjauh latihan. Hal ini mengandung pengertian bahwa interaksi belajar merupakan suatu permainan atau latihan sesuai dengan perkembangan nalar anak yang bersifat konkrit bagi anak untuk memahami, memahami dan menggunakan topik musik Emotion of Sikatuntuang. Hal ini penting bagi seorang pengajar untuk melakukan, mengetahui dan memiliki pilihan untuk membuat pembelajaran yang menarik, kreatif dan menyenangkan bagi siswa sekolah dasar, sehingga tujuan pembelajaran dapat dilakukan dengan tepat, cakap, dan memadai. Pengerahan tenaga ini dapat membuat interaksi belajar berjalan lebih baik dan sifat pencapaian hasil dapat lebih ideal, mahir. 
Guru atau Pendidik harus memiliki pengaturan yang cermat, sistem pembelajaran, pendekatan, strategi pembelajaran, dan penilaian yang akan mewajibkan kemampuan psikologis, emosional, dan psikomotor siswa sekolah dasar menuju pembelajaran yang signifikan, instruktur harus siap untuk mengubah dari teknik biasa ke strategi biasa. pembelajaran terkini dengan mengikuti perkembangan zaman dan globalisasi.

\section{Referensi}

Agung, I. (2010). Meningkatkan Kreativitas Pembelajaran Bagi Guru. Jakarta Timur: PT. Bestari Buana Murni.

Brocklehurst, B. (1971). Response to Music: Principles of Music Education. London: Alden \& Mowbray Ltd.

Djohan. (2005). Psikologi Musik. Yoyakarta: Buku Baik.

Karsono. (2011). Proses Kreatif A.T. Mahmud Dalam Penciptaan Lagu Anak-Anak. Dewa Ruci: Jurnal Pengkajian dan Penciptaan Seni. 7(1).

Kemdikbud. (2013). Implikasi Kurikulum 2013. Jakarta: Kementerian Pendidikan dan Kebudayaan.

Mustopo. (1983). Kesenian Tradisional Problematika Karawitan. Jurnal Resital ISI: Yokyakarta.

Miller, H., M. (2017). Pengantar Apresiasi Musik (Introduction to Musica, Quideto GoodListening) Terjemahan Triyono Bramantio PS (tth.)

Miles, dkk. (2014). Qualitative Data Analysis A Methods Sourcebook. United State of America: SAGE Publications, Inc.

Muhammad, A. (2010). Deteksi Bakat dan Minat Anak Sejak Dini. Jogjakarta: Garailmu.

Mulyasa, E. (2007).Menjadi Guru Profesional; Menciptakan Pembelajaran Kreatif dan Menyenangkan. Bandung: Remaja Rosdakarya.

Munandar, U. (1999). Kreativitas dan Keberbakatan. Strategi Mewujudkan Potensi Kreatif dan Bakat. Jakarta: PT. Gramedia Pustaka Utama.

Nurdiani, N. (2014). Teknik Sampling Snowball Dalam Penelitian Lapangan. Jurnal Comtech, 5(12).

Parmadie, B. (2017). "Dinamika Musik Dol Sebagai Media Pendidikan Seni Di Kota Bengkulu". Proceedings: International Conference on Primary and Early Childhood Education. Bandung: PGSD Universitas Pendidikan Indonesia.

Rozi, A. (2014). Pendidikan dalam Perspektif Teori Kritis (Ke Arah Kontekstualisasi Pendidikan Yang Membebaskan). Jurnal Pelopor Pendidikan, 5(1), 31-38.

Rusydie, S. (2011). Prinsip-Prinsip Manajemen Kelas; Tuntunan Kreatif dan Inovatif untuk keberhasilan Kegiatan Belajar-Mengajar. Jogjakarta: Diva Press.

Sukerta, P., M. (2011). Metode Penyusunan Karya Musik (Sebuah Alternatif). Kementrian Pendidikan Nasional Program Pascasarjana Institut Seni Indonesia (ISI) Surakarta.

Tolah, A., F. (2014). Proses Berkarya Grup Musik Distorsi Akustik. Catharsis: Journal of Arts Education. Semarang: UNNES

Waridi. (2003). Jurnal Pengkajian dan Penciptaan Seni. Program Pendidikan Pascasarjana Sekolah Tinggi Seni Indonesia (STSI) Surakarta. 